\title{
CURRENT TREND IN NAMING BABIES IN JAVANESE COMMUNITY
}

\author{
Carla Sih Prabandari \\ Sanata Dharma University \\ carla@dosen.usd.ac.id \\ DOI: https://doi.org/10.24071/ijhs.2017.010107 \\ received 9 May 2016; revised 28 March 2017; accepted 27 July 2017
}

\begin{abstract}
The process of naming newborn babies is inseparable from the culture where they belong. Among Javanese people, there is a change of trends in naming babies. As western, noble, and religion associated names, such as Amelia, Gupita, Arsyad, gain popularity, modest and old-fashioned names, such as Tugino and Pariyem disappear. This paper discusses the trend in the naming of babies in Javanese community at the present time. Three theories are employed in the analysis. I will apply Saussurean Semiology and Bathesian Semiology and try to relate them to Stuart Hall's Theory of Identity. As a name is just an element of cultural identities, changing trends in naming in Javanese culture does not entirely change their identity as Javanese people.
\end{abstract}

Keywords: Naming tradition, Javanese community, identity

\section{Introduction}

Naming a baby is a unique culural phenomenon in the history of humankind. Zwebner, Sellier, Rosenfeld, Goldenberg \& Mayo (2017, p 550) say that "we are subject to social structuring from the minute we are born, not only by our gender, ethnicity, and socioeconomic status, but also by the simple choice that others make in giving us our name." It suggests that naming processes cannot be separated from one's culture. This is in line with what Pina-Cabral (2008, p. 5) say that naming processes carry with them implications concerning what is a person and how he or she is placed in the world. Further, he believes that the way a person is socially constructed to some extent depends on the way the person is named.

Usually, the name of a baby can be derived from many inspirations. "Instead of personal criteria, specific rules for naming a child are more prevalent in, for example, Asian societies" (Watzlawik, Pizarroso, Guimarães, Doria, Han, Ma \& Jung, 2012, p. 1164). Such rules may be based on events that happened before or after the baby is born, the totems and families trees, or the date and time of birth of the baby. Alternatively, if a name of a baby arouses spontaneously in mind, still, it needs a thoughtful consideration to give meaning to that name. Proper names or first name can refer to many things, such as public figures, heroes or heroines, religious figures, name of a place, name of a time (calendar), 
clan, characteristics of the nature (weather, climate), characteristics of animals (showing strength, bravery), and so on.

In this paper, I will discuss the naming of babies in Javanese community at the present time. Three theories are employed in the analysis. I will apply Saussurean Semiology and Bathesian Semiology and try to relate them to Stuart Hall's Theory of Identity. I refer Javanese community to those who were born in the specific areas of Java, namely Yogyakarta province. The people in this area are heterogeneous; they come from various places, various ethnic, and they hold various religions and faith. They live in cities, suburban, and rural areas.

\section{Discussion}

Nowadays, there is a change of trend in naming babies. If we pay a visit to newly born babies in hospitals around the Yogyakarta, we will rarely find babies under the names of Tukinem, Miyatun, Partini, Sutiyem, Paijo, Martorejo, Tugino, Pardimin, and the likes. Instead, on the list of the babies' names, we will read Yenny, Merry, Tamara, Diska, Amelia, Reysha, Beny, Dino, Sony and other similar names; or other kinds of name such as Muhammad, Arsyad, Ikhsanuddin, Afifah, Choiriyah, Abdullah, Al Ma'ruf, Salsabilla, Siska, Josef, Johana, Maria, Nikolas and the likes. In the rural area of Panggang, District of Gunung Kidul, there is a young couple named Supriyatno Mujimin and Wartinem. Last year, they had a baby and named her Amelia Ayu Lestari. Another couple in the rural area in Ngaglik, Sleman District, named their baby Dicky Raharja, whose faher's name is Sukiyono. Another family in the same area, whose father's name is Tugino Warto Sentono and whose mother's name Sukinem binti Sumodirejo, have three sons named Denny Cahyono, Deddy Wijaya, and Benny Priyadi. It is not wrong, of course, to name their baby in such way. However, the question is why they should give names like Amelia, Dicky, Deny, Deddy and Benny. Why do they leave the old-fashioned names?

\section{Names: First Names, Surnames, Middle Names and Nicknames}

There are some terms related to names, i.e. first names, surnames, middle names, and nicknames. In western cultures, a person's name usually consists of two parts or two words. The first word of the name is called the first name,or given name, or forename; and the second element is the surname, or family name. Surnames refer to the father's name in patriarchal culture. Surnames often carry "impressions of ethnicity, personality, intelligence, and physical attractiveness" (Kasof, 1993: 151). Sociolinguistically, the use of first name sociolinguistically signals informal and intimate relationship, showing high solidarity. In contrast, the use of last name indicates formal relation and low solidarity. In some cases, a married woman can still use her father's name before the husband's name. In such cases, the father's name becomes the middle name, and her husband's name becomes her surname. Sometimes, a person is called by his or her nickname to show affection, ridicule, or familiarity. A nickname is a substitute for or an addtion to the proper name of a familiar person, place, or thing, for affection.

\section{Naming in Javanese Tradition}

The naming system above - the use of first name and surname - does not apply in Javanese culture. Even though in majority, Javanese people's names consist of two words, they do not follow the western system. In Javanese, the 
second element of a person's name does not necessarily refer to the name of the father - or the husband for a married woman. Thus, names such as Sri Rahayu, or Joko Rahmanto are just given names. However, the use of nicknames among the Javanese are quite common, and still they are only used to show high solidarity. Boulin and Weeks (2005, p. 17) argue that "different names can be used to emphasize different aspects of personality, degrees of warmth, and technical competence." Thus, calling someone by his nickname Gepeng, which means very skinny, for example, is only acceptable when we know the person very well, and the context is informal and intimate.

So far, there has not been any standard for naming babies in Javanese tradition. Nevertheless, it has commonly been advised that in naming a baby, we should consider some aspects concerning the situation and the condition of the baby and of the life of the parents. One of the Parents's considerations in choosing first names for their newborns is the popularity. Parents tend to avoid using popular names due to overexposure (Hargreaves, Colman and Sluckin, 1983). In general, the basic considerations in giving a name to the baby are, among others:

a. the sex of the baby (gender, biological aspect);

b. what, how, where, and when the baby was born;

c. the physical aspect of the baby's body

d. the hope for the baby's future; and

e. the family background

These five aspects are not the standard ones but they are commonly used by Javanese people in naming babies.

Sex or biological aspect is of course the primary consideration in naming a baby because there is a division of names based on the sexual properties. The name Bagus, for instance, is given to a baby boy who has handsome face (physical aspect); or he is expected to behave manly. If the baby is a baby girl, we can use the name $A y u$, which means beautiful. It is hardly possible to give a first name like Suharto to a baby girl since the last vowel in the last syllable '-to' refers to males. Instead, we can give the baby girl a name like Suharti because the last syllable '- $t i^{\prime}$ is for females. There many other signs in naming babies based on these sexual properties. The examples below are the last sounds or syllables of names which usually indicate the sex.

Table 1: Name Ending in Javanese Culture

\begin{tabular}{ll}
\hline Male & Female \\
-a. -o, -in, -an, -min, -man & -i, -ah, -inah, -nah, -yah, -em, \\
-wo, -wa, -wan & -inem, -yah, -wati
\end{tabular}

The list above is only meant to show the example of the division of names. There are other techniques to differentiate between baby girls and boys such as Bambang-Endang, Dimas- Ajeng, Bagus-Ayu. Of course, there many neutral names in Javanese tradition such as Chandra, Puspa, Kusuma, Sri, Praba, and so on. However, these neutral names need to be combined with a gender specific name endings to clarify whether the baby is a girl or a boy. Hence, we can find the 
names Prabawati (female) - Prabawa (male), Kusumaningrum (female) Kusumanto (male), Sriyati (female) - Sriyono (male) etc. Gender property is a very important aspect in naming a baby. There are other considerations for naming a baby which are all used in accordance with the importance. For example, if the parents want to show that the baby girl was born in the fasting month of Ramadhan, they can use, for example, Ramadhani. If they want to use the family name, they can put it after the first name.

\section{Categorization of Names}

Actually, we can categorize Javanese baby names into four groups. The first group belongs to what the so-called old-fashioned villagers (Javanese: ndeso) which refer to babies who were born in the rural areas. This can be found in the beginning of this paper (see paragraph 2), which includes Tukiyem, Miyatun, etc. The second group is the ones from the noble family (educated or aristocratic) such as Danutirto, Margayasa, Gupita, Harjuna, Nirmala, Kusumo, Kesawa, Brata, Narayana, and many others. The third group belongs to the 'new-fashioned' or modern ones such as Amelia, Denny, etc. The fourth group is the names originated from the religious figures; whether they are Moslems or Christians (also in paragraph 2 page 1), which includes Muhammad, Arsyad, Afifah, Siska, Josef, etc.

This categorization is not the standard one but it can show that there are different types of baby names in Javanese community. It is important to make this categorization since we will discuss which (not all) names are not used by the parents nowadays. However, if we observe the real condition and situation of the present Javanese community, we rarely find parents who call their children who might be below ten years of age by names such as Ponimin, Miyatun, Ponijan, etc. We hardly hear parents shouting, "Min, Come here!" or, "Tun, help your mother." The same condition will be found if we are in an elementary school. Those kinds of names are hardly found in the class attendance list. It is very likely, when we are living in a densely-populated residence that we hear somebody calling, "Denny, come into the house!" or, "Alsa, finish your work!" These kinds of name are now easily found in Javanese community. New generation parents now do not give their babies names which are considered 'old-fashioned'. They prefer to use other kinds of name.

Is That Modern or... ?

In many places where different cultures come into contact, the naming tradition may change. An obvious example can be found in Hong Kong, where the Eastern hierarchical culture meets the Western egalitarian culture. Many Chinese Hongkongers use English names along with their Chinese names (Watzlawik et al., 2012). In Macau, "it is common for Portuguese people to have a Chinese name and for Chinese people to have a Portuguese or English first name" (Pina-Cabral \& Lourenço, 1994, p. 126).

Compared to the other ethnic group in Indonesia, for example Balinese or Batak, Javanese parents are not proud anymore to use typical Javanese names such as Tugino, Painah, Wakijan, Tuminem, etc. Unlike the Javanese, people of Bali or Batak still use their typical names. In Bali, we still hear the names Kadek, Wayan, Made, etc. or in Batak, we can still hear many people call Tobing, Butet, Poltak, etc. The reason why the Javanese parents leave those names is simply that 
they are old-fashioned, not modern as they live in the modern world. They feel embarrassed to give such names to their children whilst at the same time there are still many other new-fashioned names.

\section{What is in a name!}

A name is not simply a name. It has a meaning. A name is not just a word of a language. A name, in Saussure's semiology, is a sign. Paijo signifies something or it refers exactly to a person; and so do the other names, Sumiyatun, Tukijan, Sarjimin, Painah, etc., refer to certain people who belong to certain group of a culture, namely Javanese community. If we mention Pariyem, in our mind we have made an object of a Javanese woman. It might include the description of how she looks like, what kind of dress she wears, how tall she is, how she speak, and so forth. Using the signification model proposed by Saussure (Easthope \& McGowan, 1992, p. 9), we can describe it into the diagram below.

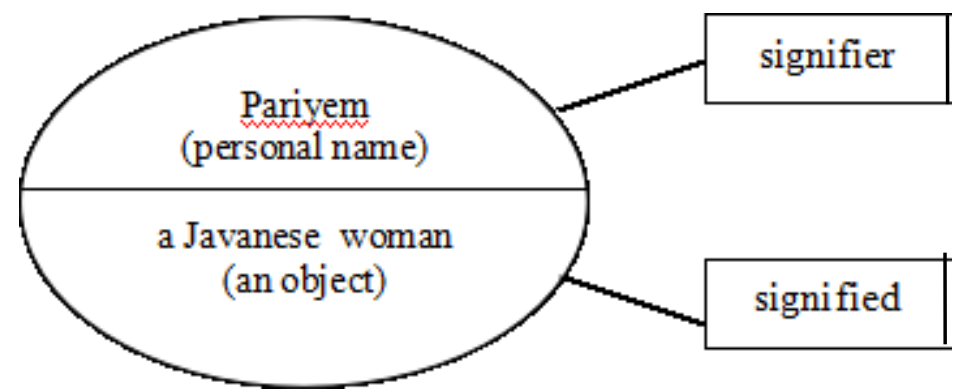

Figure 1: Personal Name in Saussure's Semiology

The relation between a personal name, Pariyem, and a Javanese woman (it can be a pictorial object) creates the sign of a name. In other words, we can also use many diagrams to show that certain words such as Paijo, Sukinem, Tugimin, Wakijan, etc refer to Javanese persons, in many diagram because every name is a signification of different objects. However, we can categorize them into a value that is Javanese name. Although the diagram concerns with the language, Saussure said, it can also show the other social fact (or the culture) of certain community, which is different form one community to another. (Easthope \& McGowan, 1992, p. 68; see also Lehtonen, 2000, p. 36). The signification of Pariyem, Paijo, Sukinem, etc. is not the representation of the facts; they construct the facts, as the language does. Thus, name contains a social fact that is about person with his or her attributes. A name becomes an identity.

\section{Name as a Myth}

Saussure, by creating a diagram of signification or semiological system, has shown how a word of language could produce the social fact. Yet, he just discussed it in terms of the language plane. This level is called the linguistic semiology. Barthes develops this concept of signification and extends it to the plane of myth in the semiological system. In Barthes' semiology, there are two levels of signification: the first is the language and the second is the myth itself. Myth, according to Rolland Barthes (1975), is a type of speech. It exists in every culture in the forms oral speech. It consists of modes writing of or representation. (Easthope \& McGowan, 1992, p. 15). Therefore, Barthesian semiology is called cultural semiology. 
The development of the signification is shown in the diagram below. The result of the signification (the correlation between the signifier and the signified) in the first level is considered as the signifier of the second level that is the level of myth. This signifier, then, is used to signify something (the signified of the second level). The result of signification in the second level is called the second sign. The following diagram explains Barthes' Semiology, which is based on Saussure's Semiology.

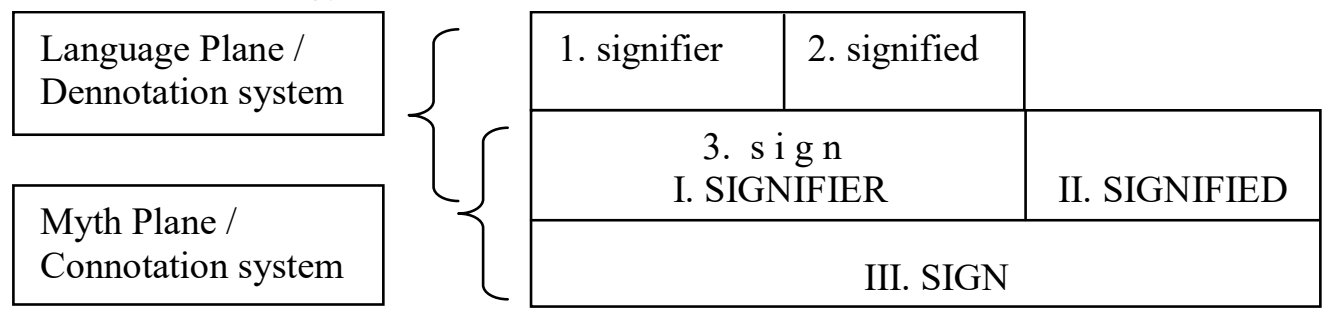

Figure 2: Barthes' Semiology and Saussure's Semiology

In Elements of Semiology (1967, p. 89), Barthes, borrowing Hjemselv's terminology, called the first level of semiological system (language plane) the denotation system and the second level (the myth level) the connotation system. This clarification, therefore, can help us understand and use Barthes's semiological system. As in the case of Pariyem in Saussure's model of signification, it signifies a name or an identity of a Javanese woman. This signification - the identity - becomes the signifier in the second level of the connotation system. It signifies the Javanese people. Applying it into the diagram of Barthes's semilogical system, we find the correlation between the identity and the Javanese community, which means the identity of the Javanese.

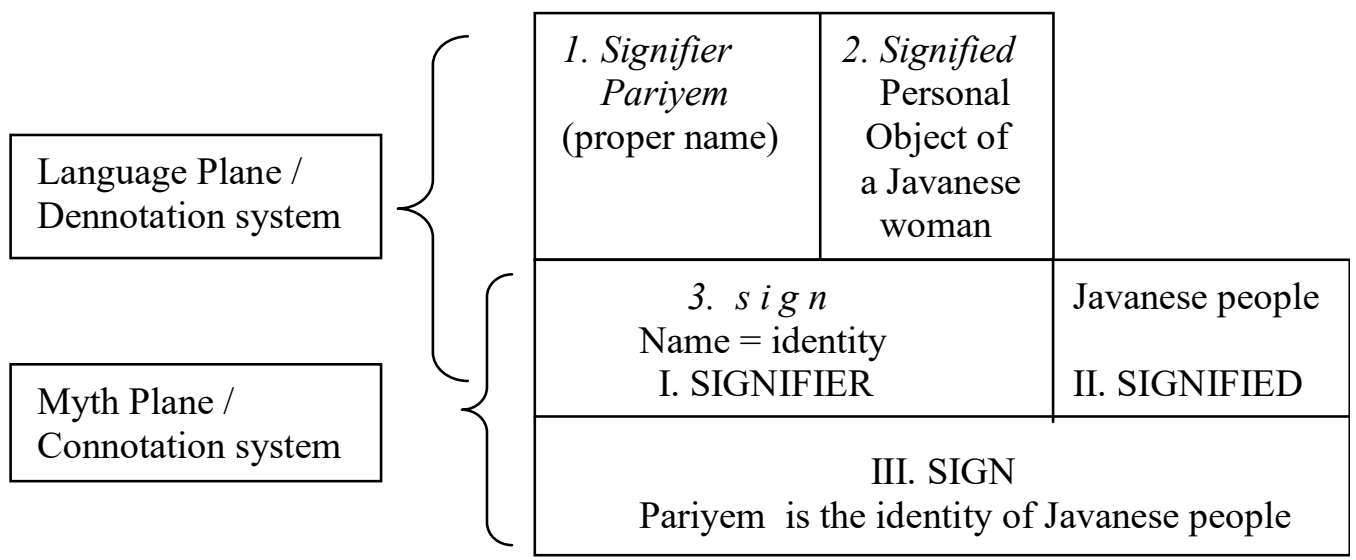

Figure 3: Pariyem in Barthes's Semilogical System

From the result of signification in the myth planes, we can differentiate this identity from the identity of other community, such as those of Balinese and Batak. We can also make the differentiation between that identities - being an old-fashioned name - with those of the new-fashioned or modern name. The signification process using the connotation system has created the myth, that Pariyem, Wakijan, Tukiran, Sutinah, etc. are the identities of Javanese people, especially those who lived in the past generation in the rural areas. This myth has 
existed in the area of Yogyakarta since a long time ago. The parents in this area gave their babies such names. They thought that these were common names, which differentiated their community from others.

\section{Losing the Cultural Identity}

Parents, including Javanese parents, still believe that a name given to a child is a prayer. It carries expectation from the parents and a wish about the child's future. As as also stated by Windt-Val, (2012, p. 273) that "the parents' choice of name for their child will have an influence on the development of the personality of the child." Let's return to the question, "Why do they leave the oldfashioned names?" The new generation of parents is likely to say that those names, such as Paijo, Waginem, and so on, are out of date. If they gave such names to their babies, they would feel embarrassed. They think that their neighbours would stigmatize their children as traditional or old-fashioned boys or girls (Javanese: ndeso). They believe that using religious and modern names would prevent them from this stigmatization. Moreover, they are not worried about losing their identity. We have discussed that a name produces an identity of person. Furthermore, in the myth system, we have also signified that the name represents the cultural identity, in this case, the Javanese people. Talking about identity, we cannot separate it from the discussion of a discourse. Stuart Hall (1996) says that identities are constructed through, not outside, difference; it is only through the relation to the other. Identities are not natural possessions; they are constructed in a social discourse in order to emphasize the differences among the members.

In Javanese community, as we have discussed in the early sections, there are groups of names. Each of them shows their own characteristics: the old-fashioned, the noble, the religious, and the modern ones. All of them construct different identities among the Javanese people. However, the old-fashioned ones raise the problem among the Javanese people. Many of them, now, do not want to use them. They think that those names construct traditional values, not modern and not noble or not religius. Using the names, such as Merry, Tamara, Diska, Amelia, Reysha, Beny, Dino, Sony and the likes, will construct modern values. These names are not of the Javanese identities; they are assumed as the names of metropolitan citizens. Giving the babies names like Muhammad, Arsyad, Ikhsanuddin, Afifah, Choiriyah, Abdullah, Al Ma'ruf, Salsabilla, Siska, Josef, Johana, Maria, Nikolas, etc., will construct religious values. If they give such kinds of name to their babies, people will think that they and their children hold the faith to God, being religious persons. Giving the names such as Danutirto, Margayasa, Gupita, Harjuna, Nirmala, Kusumo, Kesawa, to the babies will construct the noble values. People will think that children with this kind of names come from the respectable families.

Proper name is a discourse, and so is cultural identity. Name is just one part of the cultural identities. There are many other things that show cultural identities such as fashions, housings, rites, traditions, and so on. However, they are all constructed in a discourse. Leaving the old-fashioned names out of the new generation does not mean that they lose their cultural identities. It just constructs new discourse of identity. 


\section{Conclusion}

Language is not the representation of social facts but it produces social fact. This can be shown by using Saussurean Semiology, which is the basis for all significations of social and cultural phenomena. However, it refers mainly to the linguistic aspect; it denotes things or persons. The correlation between the signifier and the signified is positive and explicit. Hence, the result of signification is just one meaning. Using Saussure's semiological system, Barthes has expanded this kind of signification. He added another order of signification so that we can find two levels of signification: first in the level of language and the other in the level of myth. The first one is the denotation system and the other is the connotation system. Barthes's semiological system has more tools to analyze cultural and social phenomena that are the myth, the result of signification process. In this myth, the correlation between the signifier and the signified can be both negative and positive, and usually it is implicit. Since a name is just an element of cultural identities, the change of trend in naming children in Javanese community, therefore, does not entirely change the Javanese people identities.

\section{References}

Barthes, R. (1967). Elements of semiolog. (Annette Lavers \& Colin Smith, Trans.). New York: Hill and Wang.

Bolin, A. U. \& Weeks, N. (2005). The effects of first name stereotypes on ratings of job applicants: Is there a difference between Bill and William? American Journal of Psychological Research, 1(1), 11-20.

Easthope, A. \& McGowan, K. (Eds.). (1992). A critical and cultural theory reader. Toronto: University of Toronto Press.

Hall, S. (Ed.). (1996). Questions of cultural identity. London: Sage Publications.

Hargreaves, D.J., Colman, A.M. and Sluckin, W. (1983). The attractiveness of names. Human Relations, 36(4), 393-402.

Kasof, J. (1993) Sex bias in the naming of stimulus persons. Psychological Bulletin, 113(1), 140-163.

Lehtonen, M. (2000). Cultural analysis of texts. London: Sage Publications.

Pina-Cabral, J. (2008). What's in a name: Personal identity and linguistic diversity in a cosmopolitan world. Paper presented at the Symposium on Multilingualism and Intercultural Dialogue in Globalization, New Delhi.

Watzlawik, M., Pizarroso, N., Guimarães, D.S., Doria, N.G., Han, M., Ma, C. \& Jung, A.J. (2012). Proceedings of the 10th World Congress of IASS: First Names as Signs of Personal Identity: An Intercultural Comparison. Proceedings of the 10th World Congress of IASS. (pp. 1159-1176).

Windt-Val, B. (2012). Personal names and identity in literary contexts: Names and identities. Oslo Studies in Language 4(2), 273-284.

Zwebner, Y., Sellier, A., Rosenfeld, N., Goldenberg, J. \& Mayo, R. (2017). We look like our names: The manifestation of name stereotypes in facial appearance. Journal of Personality and Social Psychology, 112(4), 527554. doi: $10.1037 / \mathrm{pspa0000076}$ 